\title{
Perspective on Recent Developments on Sulfur-Containing Agents and Hydrogen Sulfide Signaling
}

Author

Affiliation
Claus Jacob, Awais Anwar, Torsten Burkholz

Division of Bioorganic Chemistry, School of Pharmacy, Universität des Saarlandes, Saarbrücken, Germany
Key words

- natural sulfur products

- garlic

polysulfides

- hydrogen sulfide

- vascular homeostasis

received May 7, 2008

revised July 9,2008

accepted July 30, 2008

Bibliography

DOI 10.1055/s-0028-1088299

Planta Med 2008; 74: 1580-

1592

(c) Georg Thieme Verlag KG

Stuttgart · New York

Published online October 20,

2008

ISSN 0032-0943

\section{Correspondence}

\section{Prof. Dr. Claus Jacob}

Division of Bioorganic Chemistry School of Pharmacy

Universität des Saarlandes

Campus B 2.1

PO Box 151150

66041 Saarbrücken

Germany

Tel.: $+49 / 681 / 302 / 3129$

Fax: $+49 / 681 / 302 / 3464$

c.jacob@mx.uni-saarland.de

\section{Abstract \\ $\nabla$}

The last couple of years have witnessed the coming together of several initially unconnected lines of investigation which now link natural sulfur products to hydrogen sulfide release and wide ranging cardiovascular protection. It has become apparent that sulfur compounds contained within garlic, onions, mushrooms and various edible beans and fruits may be transformed chemically or enzymatically in the human body with subsequent formation of hydrogen sulfide. The latter has emerged during the last decade from a shadowy existence as toxic gas to be recognized as the third gaseous transmitter besides nitric oxide ('NO) and carbon monoxide (CO). Hydrogen sulfide is formed endogenously in the human body by enzymes such as cystathionine $\beta$-synthase (CBS) in the brain and cystathionine $\gamma$-lyase (CSE) in liver, vascular and non-vascular smooth muscle. Although its exact chemical and biochemical modes of action are still not fully understood, levels of hydrogen sulfide in the brain and vasculature have unambiguously been associated with human health and disease. Not surprisingly, agents releasing hydrogen sulfide, as well as inhibitors of hydrogen sulfide synthesis (CBS and CSE inhibitors) have been investigated. Apart from linking our daily diet to a healthy brain and cardiovasculature, these findings may also provide new leads for drug design. Future studies will therefore need to focus on how such compounds are formed and transformed in the relevant plants, how food processing affects their chemical constitution, and how they release hy-

\section{Introduction \\ $\nabla$}

Garlic, onions, leek and related culinary vegetables of the genus Allium have been valued for their apparent benefits to human health for drogen sulfide (or control its levels) in the human body. Such multidisciplinary research should ultimately answer the all-important question if a hearty diet is also good for the heart.

\section{Abbreviations \\ $\nabla$}

AAT: aspartate aminotransferase

AM: allyl mercaptan

APS: adenosine 5'-phosphosulfate

BCA: $\beta$-cyanoalanine

cAMP: $3^{\prime}, 5^{\prime}$-cyclic adenosine monophosphate

CBS: $\quad$ cystathionine $\beta$-synthase

CSE: cystathionine $\gamma$-lyase

DADS: diallyl disulfide

DAS: diallyl sulfide

DATS: diallyl trisulfide

DATTS: diallyl tetrasulfide

GSH: glutathione (reduced)

GSSG: glutathione disulfide

MPST: 3-mercaptopyruvate sulfur transferase

RSS: reactive sulfur species

SAC: $\quad$-allylcysteine

SAM: $S$-adenosylmethionine

SIR: $\quad$ sulfur-induced resistance

SO: $\quad$ sulfur oxidase

TSMT: thiol S-methyl transferase many centuries and all over the world. Antibacterial, antifungal and antiviral properties in particular have long been ascribed to garlic, onions, their oils and extracts [1]. Garlic, for instance, has been dubbed the 'Russian penicillin' for its 


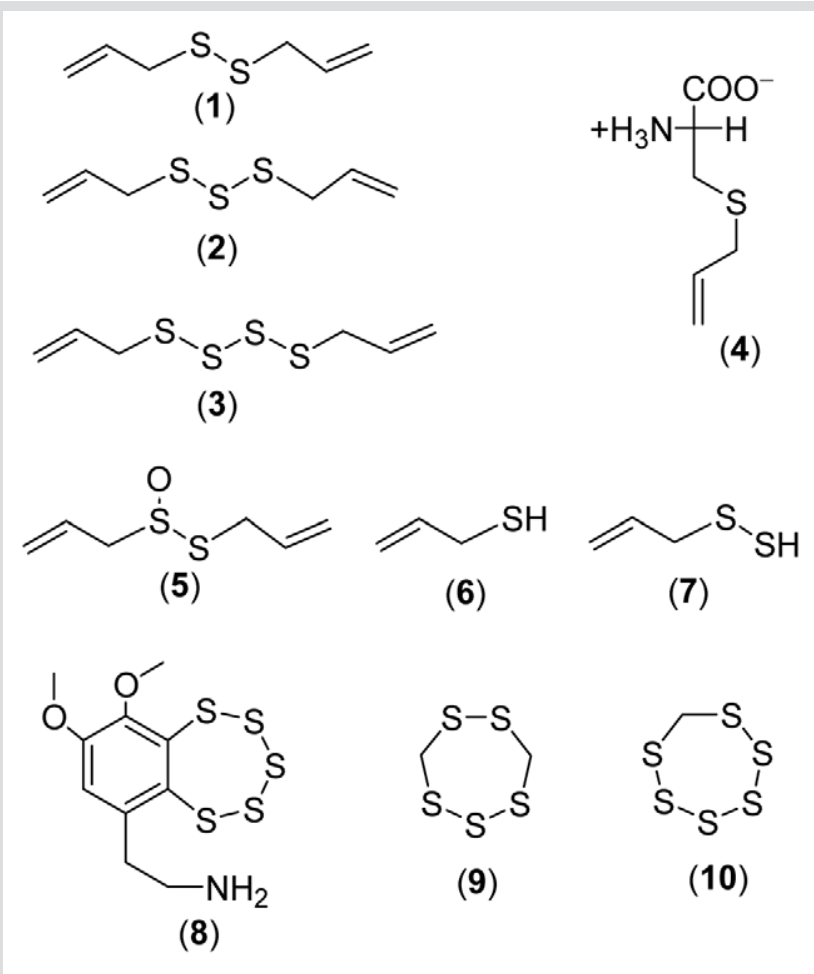

Fig. 1 A selection of natural sulfur compounds whose occurrence in plants, mushrooms, and algae has been associated with the formation of hydrogen sulfide: DADS (1), DATS (2), DATTS (3), S-allylcysteine (4), allicin (5), allyl mercaptan (6), allyl perthiol (7), varacin (8), lenthionine (9), 1,2,3,4,5,6hexathiepane (10) [1].

use as an antibiotic during both World Wars [2]. Scrutinized by modern science, many of these apparent health benefits of garlic, onions and related plants have turned out to be little more than popular myths. Nonetheless, most Allium vegetables are rich in rather interesting, biologically active compounds and provide a treasure chest of sulfur (and non-sulfur) compounds, some of them even in extraordinarily high concentrations (० Fig. 1).

Most of the research on sulfur chemistry in garlic and other Allium plants has taken off shortly after the Second World War and has been a focus of intense research during the $1970 \mathrm{~s}$ and $1980 \mathrm{~s}$ (this period has been reviewed in 1992 by Eric Block [3]). During the last decade or so, investigations of naturally occurring sulfur compounds have experienced a certain renaissance, fuelled by a combination of new discoveries in the field of biological sulfur (redox) chemistry and cellular redox signaling, promising new results obtained in a range of biological activity studies employing natural sulfur products and, last but not least, a strong demand for novel, innovative medicines and 'green pesticides' to deal with some of the challenges of the $21^{\text {st }}$ Century. ${ }^{1}$ Among the various discoveries made in this field during the last couple of years, three developments have contributed significantly to the current interest in (natural) sulfur compounds. Firstly, the protein sulfiredoxin (Srx) has been described for the

\footnotetext{
${ }^{1}$ These challenges include the search for agents able to tackle multi-drug resistant bacteria, selective anticancer agents, chemopreventive agents suitable to deal with diseases characteristic of an ageing society and readily available 'green pesticides' which kill pests but do not contaminate the food chain or ruin the eco-system. Natural sulfur agents have been considered as part of all of these challenges.
}

first time by Michel Toledano and colleagues in yeast in 2003, and has later also been identified in humans [4]. This protein is highly unusual, since it is able to reduce cysteinesulfinic acid in the (overoxidized) peroxiredoxin enzyme to cysteinesulfenic acid. Together with the emerging concept of reactive sulfur species (RSS), which has been promoted during 2001 and 2002 [5], this discovery has opened the door to a novel and quite unexpected sulfur redox chemistry in vivo, which has had a profound impact on our understanding of RSS in human biochemistry and their pivotal roles in intracellular redox signaling and control. Secondly, a rather extensive study by Rex Munday and colleagues, also published in 2003, has shown that the biological polysulfide chemistry, which has long been associated with garlic and onions, but also a couple of other plants, algae and mushrooms, may be more complex than thought previously [6]..$^{2}$ For instance, the ability of polysulfides to (catalytically) generate superoxide radicals and thereby modulate the intracellular redox state, has attracted considerable interest, not least in the area of redox signaling, apoptosis and anticancer research. Up to this point the thiosulfinate allicin had been considered as the dominant 'active ingredient' of garlic, and this notion is changing now.

Studying the anticancer activity of polysulfides, Shivendra Singh and colleagues in 2005 reported that polysulfides, such as diallyl trisulfide (DATS), are able to effectively kill certain cancer cells, such as prostate cancer cells (PC-3), whilst hardly affecting healthy prostate (epithelial) cells (PrEC) [7]. This rather astonishing finding of high efficiency and selectivity associated with a chemically rather 'primitive' molecule has now been confirmed by other, independent studies and may well provide new leads for the development of novel anticancer agents [8], [9], [10], [11]. ${ }^{3}$ It is also in line with various previous studies which have reported significant antimicrobial (e.g., antibacterial, antiviral, fungicidal, nematocidal) activities of DATS and diallyl tetrasulfide (DATTS), activities often comparable to the ones of the benchmark compound allicin [1], [12].

Up to this point, the polysulfide success story, however, has had one major drawback: while the basic chemistry of polysulfides in vitro has been rather well known for several decades [13], the behavior of this 'chemotype' in vivo appears to be somewhat more complex. This matter has recently formed part of a Perspective on the chemistry of natural sulfur agents, which has collected the rather scattered literature evidence on biological polysulfide chemistry up to 2007 and, based on this evidence, has proposed almost ten different realistic modes of (chemical) reaction and action of polysulfides in vivo, some of which will be mentioned later on [14].

\footnotetext{
${ }^{2}$ We will use the term 'polysulfide' to denote organic and inorganic sulfur species which contain sulfur-sulfur chains with chain lengths of three or more sulfur atoms. This is due to the fact that most natural, organic compounds discussed here are commonly known as 'sulfides', such as diallyl trisulfide. Please note, however, that strictly speaking organic molecules containing such groups $\left(R S_{x} R, x \geq 3, R \neq H\right)$ should be referred to as `polysulfanes', while inorganic species of the type $\mathrm{S}_{\mathrm{x}}{ }^{2-}(\mathrm{x} \geq 3)$ should be called 'polysulfides'.

${ }^{3}$ Within this context, one should also point out that unlike most anticancer drugs of natural origin, diallyl trisulfide and related agents occur in edible plants, are considered non-toxic to humans and have formed part of the human diet for centuries.
} 
Table 1 Overview of selected, naturally occurring sulfur species able to generate hydrogen sulfide. The (common) names, general chemical formulas, sulfur oxidation state(s) and important aspects of the occurrence, formation and reactivity are given, with a particular focus on their ability to generate hydrogen sulfide. See text and figures for further details. Please note that this table is necessarily incomplete. Hydrogen sulfide release from these compounds is mostly based in evidence obtained in vitro and, as far as release in vivo is concerned, is therefore speculative at times.

\begin{tabular}{|c|c|c|c|c|c|}
\hline Name & Formula & $\begin{array}{l}\text { Sulfur oxidation } \\
\text { state }(R=+1)\end{array}$ & Occurrence (in Nature) & Reactivity & Hydrogen sulfide release \\
\hline Monosulfide & RSR & -2 & $\begin{array}{l}\text { dialkyl sulfides, diallyl } \\
\text { sulfides, cystathionine, SAC }\end{array}$ & $\begin{array}{l}\text { form sulfoxides, sulfones, } \\
\text { cleaved by C-S lyases }\end{array}$ & $\begin{array}{l}\text { postulated for SAC, possibly } \\
\text { catalyzed by C-S lyases }\end{array}$ \\
\hline Disulfide & RSSR & -1 & $\begin{array}{l}\text { Dialkyl disulfides, DADS, } \\
\text { cystine }\end{array}$ & $\begin{array}{l}\text { thiol/disulfide exchange, } \\
\text { cleavage at } \alpha \text { - and/or olefin- } \\
\text { ic carbon }\end{array}$ & $\begin{array}{l}\text { possible when attacked by } \\
\text { nucleophile at } \alpha \text { - and/or } \\
\text { olefinic carbon }\end{array}$ \\
\hline Trisulfide & RSSSR & $-1,0,-1$ & DATS, calicheamicin $\gamma 1$ & $\begin{array}{l}\text { exchange reactions, } \\
\text { C-S bond cleavage }\end{array}$ & $\begin{array}{l}\text { via RSSH and possibly via } \\
\text { RSSSH }\end{array}$ \\
\hline Tetrasulfide & RSSSSR & $-1,0,0,-1$ & DATTS & $\begin{array}{l}\text { exchange reactions, } \\
\text { C-S-bond cleavage }\end{array}$ & $\begin{array}{l}\text { via RSSH and possibly via } \\
\mathrm{S}_{2}^{2-}, \mathrm{RSSSH}, \mathrm{RSSSSH}\end{array}$ \\
\hline Pentasulfide & RSSSSSR & $-1,0,0,0,-1$ & varacin & $\begin{array}{l}\text { mostly exchange reactions, } \\
\text { release of } \mathrm{RS}_{x} \mathrm{H}, \mathrm{S}_{x}, \mathrm{~S}_{x}^{2-}\end{array}$ & $\begin{array}{l}\text { via full reduction of sulfur- } \\
\text { sulfur chain }\end{array}$ \\
\hline Polysulfide & $\mathrm{RS}_{x} R(x \geq 3)$ & $-1,0_{(x-2)},-1$ & $\begin{array}{l}\text { in aged/heated garlic, } \\
\text { onions }\end{array}$ & $\begin{array}{l}\text { mostly exchange reactions, } \\
\text { release of } \mathrm{RS}_{x} \mathrm{H}, \mathrm{S}_{\mathrm{x}}, \mathrm{S}_{\mathrm{x}}^{2-}\end{array}$ & $\begin{array}{l}\text { via full reduction of sulfur- } \\
\text { sulfur chain }\end{array}$ \\
\hline Thiol & RSH & -2 & $\begin{array}{l}\text { allyl mercaptan, cysteine, } \\
\text { GSH }\end{array}$ & reducing, metal binding & $\begin{array}{l}\text { possibly via C-S bond cleav- } \\
\text { age, indirectly via RSSH or } \\
\text { RSSR }\end{array}$ \\
\hline Perthiol & RSSH & -1 & allyl perthiol, thiocysteine & $\begin{array}{l}\text { formed by reduction of } \\
R_{x} R \text {, reaction of } R S H \text { with } \\
\text { sulfur }\end{array}$ & 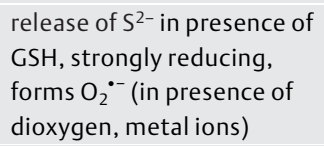 \\
\hline $\begin{array}{l}\text { Hydro-poly- } \\
\text { sulfide }\end{array}$ & $\mathrm{RS}_{x} \mathrm{H}(\mathrm{x} \geq 3)$ & $-1,0_{(x-2)},-1$ & allyl hydrosulfides & $\begin{array}{l}\text { formed by reduction of } \\
R_{x} R \text {, reaction of } R S H \text { with } \\
\text { sulfur }\end{array}$ & $\begin{array}{l}\text { release of } \mathrm{S}^{2-}, \mathrm{S}_{\mathrm{x}}^{2-} \text { in pres- } \\
\text { ence of } \mathrm{GSH}, \text { strongly reduc- } \\
\text { ing, forms } \mathrm{O}_{2}{ }^{--} \text {(in presence } \\
\text { of dioxygen, metal ions) }\end{array}$ \\
\hline Sulfide anion & $\mathrm{S}^{2-}$ & -2 & $\begin{array}{l}\text { metal/sulfur clusters, } \mathrm{H}_{2} \mathrm{~S} \text {, } \\
\mathrm{HS}^{-}\end{array}$ & $\begin{array}{l}\text { release from metal/sulfur } \\
\text { clusters at low pH, various } \\
\text { chemical, enzymatic forma- } \\
\text { tion pathways }\end{array}$ & protonation to $\mathrm{HS}^{-}$and $\mathrm{H}_{2} \mathrm{~S}$ \\
\hline $\begin{array}{l}\text { Polysulfide } \\
\text { anion }\end{array}$ & $S_{x}^{2-}(x \geq 2)$ & $-1,0_{(x-2)},-1$ & $\begin{array}{l}\text { possibly released from poly- } \\
\text { sulfides }\end{array}$ & $\begin{array}{l}\text { released from } \mathrm{RS}_{x} \mathrm{R} \text { by re- } \\
\text { duction, e.g., in presence of } \\
\text { GSH }\end{array}$ & $\begin{array}{l}\text { releases } \mathrm{S}^{2-} \text { when reduced, } \\
\text { e.g., by GSH }\end{array}$ \\
\hline
\end{tabular}

\section{Garlic and the Rotten Egg Connection' \\ $\nabla$}

One particular reaction, which has caught the attention of chemists, biochemists and cell biologists during the last two years, is the release of hydrogen sulfide from several sulfur-containing garlic compounds. This event has been discussed in quite some detail in the literature in 2007. Here, three publications need to be mentioned which have appeared within seven months of each other. In April 2007, our own group has speculated in the above-mentioned Perspective about the release of inorganic sulfide ions' from polysulfides as one possible reaction pathway open to polysulfides which may be of biochemical importance [14]. At this stage, experimental evidence of sulfide release from DATS or DATTS in living cells has at large still been lacking. Extensive experimental evidence for hydrogen sulfide release from diallyl disulfide (DADS) and DATS - and vasoactivity associated with this process - has been provided by David Kraus and colleagues just four months later, in November 2007 [15], [16]. While this report deals with $\mathrm{H}_{2} \mathrm{~S}$ release from DADS, DATS, and, implicitly, also with higher polysulfides (such as DATTS), Zhu and colleagues have been able to link hydrogen sulfide and cardioprotective effects to another ingredient of garlic, i.e., S-allylcysteine (SAC) [17]. These findings were published in August 2007 and, together with the two other papers, have provided the basis for a range of exciting new ideas in the area of natural sulfur products, Allium research, hydrogen sulfide biochemistry and possible practical applications of sulfur agents in medicine and agriculture.

Within this context, the chemistry and biochemistry of mono-, di-, tri- and tetrasulfides as well as related perthiols, hydropolysulfides and inorganic sulfides (such as hydrogen sulfide or, more generally, $\mathrm{H}_{2} \mathrm{~S}_{\mathrm{x}}(\mathrm{x} \geq 1)$ species) is now taking center stage. A selection of these chemotypes is shown in Fig. 1, some of their properties are listed in $\bullet$ Table 1 and a brief overview of their ability to release hydrogen sulfide is given in Fig. 2 . Needless to say, these listings are necessarily incomplete and the true chemistry and biochemical impact of these chemical species is highly complicated and is still only poorly understood. Here, we will therefore focus on the issues surrounding the inorganic side of organic sulfur compounds, i. e., hydrogen sulfide release, bearing in mind that there is also a huge (biological) chemistry of mono-, di-, tri- and tetrasulfides transcending $\mathrm{H}_{2} \mathrm{~S}_{\mathrm{x}}$ release.

\section{Hydrogen Sulfide as the Third Gasotransmitter}

Before we start, we must briefly consider the biochemical importance of hydrogen sulfide as a gaseous transmitter ('gasotransmitter'), a concept which in itself is only just emerging. Hydro- 


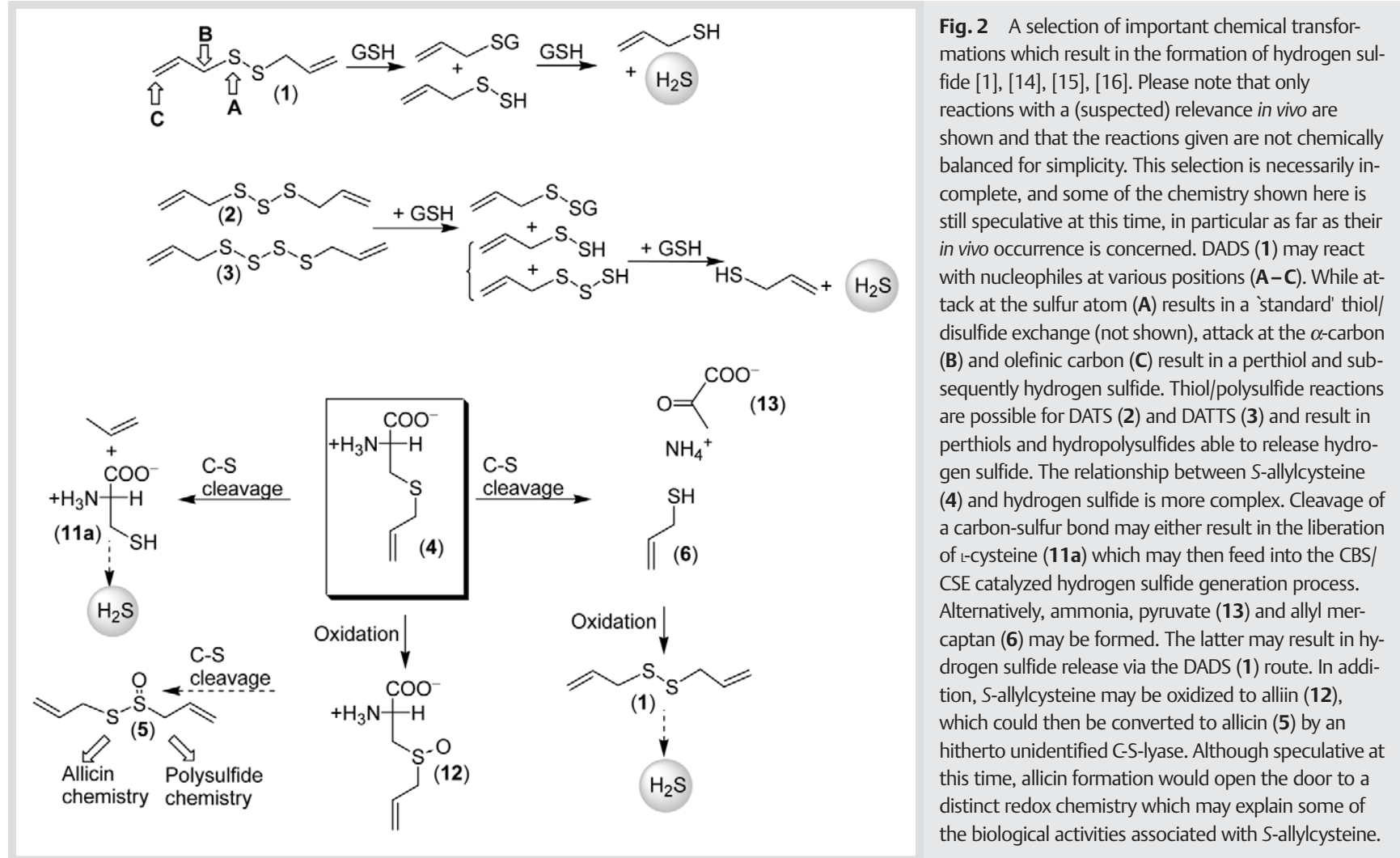

gen sulfide has long been considered as a toxic, highly poisonous gas. Indeed, $\mathrm{H}_{2} \mathrm{~S}$ gas must be considered as more toxic than hydrogen cyanide $(\mathrm{HCN})$ and inhalation of this gas may lead to severe damage [18]: it can cause irritation to the eyes and pulmonary edema when present in the lung at concentrations above $250 \mathrm{ppm}$. If inhaled at concentrations above 1,000 ppm, hydrogen sulfide rapidly leads to coma and ultimately death [19]. Nonetheless, we now know that hydrogen sulfide also plays an important, probably even pivotal role in human health and disease as the third gaseous transmitter besides nitric oxide ( $\left.{ }^{*} \mathrm{NO}\right)$ and carbon monoxide (CO). ${ }^{4}$ In this regard, $\mathrm{H}_{2} \mathrm{~S}$ shares a common 'history' with the other two gaseous transmitters: All three gases were initially considered as nasty, toxic agents, and have only slowly emerged as beneficial substances which are well integrated into the cellular machinery of the human body. The scientific process of recognizing gases as cellular signal transmitters has begun in the $1980 \mathrm{~s}$ when ${ }^{\mathrm{NO}}$ was identified as the endothelium-derived relaxing factor (EDRF), a surprising finding which has had substantial knock-on effects [20]. The discovery of 'NO as signal transmitter has been followed by new insights into the biological function of $\mathrm{CO}$, which has been known to be formed endogenously in humans since 1963 [21] and has become a focus of interest in the late $1980 \mathrm{~s}$ and $1990 \mathrm{~s}$. Finally, the role of hydrogen sulfide in human neuromodulation has emerged, first described by Abe and Kimura in 1996 [22]. The process of identifying new and beneficial roles for old gases is still continuing, with speculation ripe about mediator roles for ammonia $\left(\mathrm{NH}_{3}\right)$, acetaldehyde $\left(\mathrm{CH}_{3} \mathrm{CHO}\right)$, sulfur dioxide $\left(\mathrm{SO}_{2}\right)$ and perhaps even nitrous oxide $\left(\mathrm{N}_{2} \mathrm{O}\right)$ [18].

\footnotetext{
${ }^{4}$ Without wanting to spoil the recent excitement, from a chemist's point of view, hydrogen sulfide is not really just a 'gas' at pH 7.4, but is mostly deprotonated to $\mathrm{HS}^{-}$(see below). It would therefore rather qualify as an 'anionic transmitter'.
}

A recent review on this subject by Csaba Szabó has compared some of the chemical and biochemical properties of ${ }^{\mathrm{NO}}, \mathrm{CO}$ and $\mathrm{H}_{2} \mathrm{~S}$ which endow these gaseous molecules with important cellular functions [23]. In some ways, this list of properties also sets important criteria for other gases which may be candidates for cell signaling molecules and mediators. Among these criteria, we will briefly consider the formation in vivo, measurable presence in the organism, transport, availability of target molecules/ sites, regulatory systems able to increase or decrease intracellular levels of the mediator and pronounced effects on biochemical processes as the hallmarks of an effective gaseous mediator. Hydrogen sulfide fulfils all of these criteria. It is formed endogenously in the human body (and, indeed in mammals in general) by several enzymatic and non-enzymatic pathways, primarily in the brain and in the vasculature, but also in liver, kidney and possibly erythrocytes. The concentrations of endogenous hydrogen sulfide vary considerably between different organs. It is found in mammalian serum at concentrations of around 30 to $100 \mu \mathrm{M}$ [19], [24]. ${ }^{5}$ In the brain, concentrations of between 50 to $160 \mu \mathrm{M}$ hydrogen sulfide are commonly observed, formed primarily from cysteine ${ }^{6}$ and homocysteine by the enzyme cystathionine $\beta$-synthase (CBS) [19], [23]. Similarly, micromolar con-

\footnotetext{
${ }^{5}$ We will use the term 'hydrogen sulfide' to denote $\mathrm{H}_{2} \mathrm{~S}$ gas, the hydrogen sulfide anion $\left(\mathrm{HS}^{-}\right)$and the sulfide anion $\left(\mathrm{S}^{2-}\right)$, bearing in mind that the first $\mathrm{pKa}$ of $\mathrm{H}_{2} \mathrm{~S}$, i. e., $\mathrm{pKa}$, is 6.96 and therefore $\mathrm{H}_{2} \mathrm{~S}$ is to roughly two-thirds deprotonated (to $\mathrm{HS}^{-}$) at physiological $\mathrm{pH}$. The second $\mathrm{pKa}$ value describing the dissociation of $\mathrm{HS}^{-}$to $\mathrm{H}^{+}$and $\mathrm{S}^{2-}$ has been estimated to be around 17 to 21, i. e., this dissociation process plays no direct role in vivo, although (bound) $\mathrm{S}^{2-}$ may be formed due to interactions with 'third parties', such as $\mathrm{S}^{2-}$ ions bound to metal ions. We will use the appropriate chemical formulas, i.e., $\mathrm{H}_{2} \mathrm{~S}, \mathrm{HS}^{-}$and $\mathrm{S}^{2-}$ when referring to a particular (de)-protonation state of hydrogen sulfide.

${ }^{6}$ We refer here generally to L-cysteine. Where relevant, we will explicitly distinguish between the two isomers.
} 
A

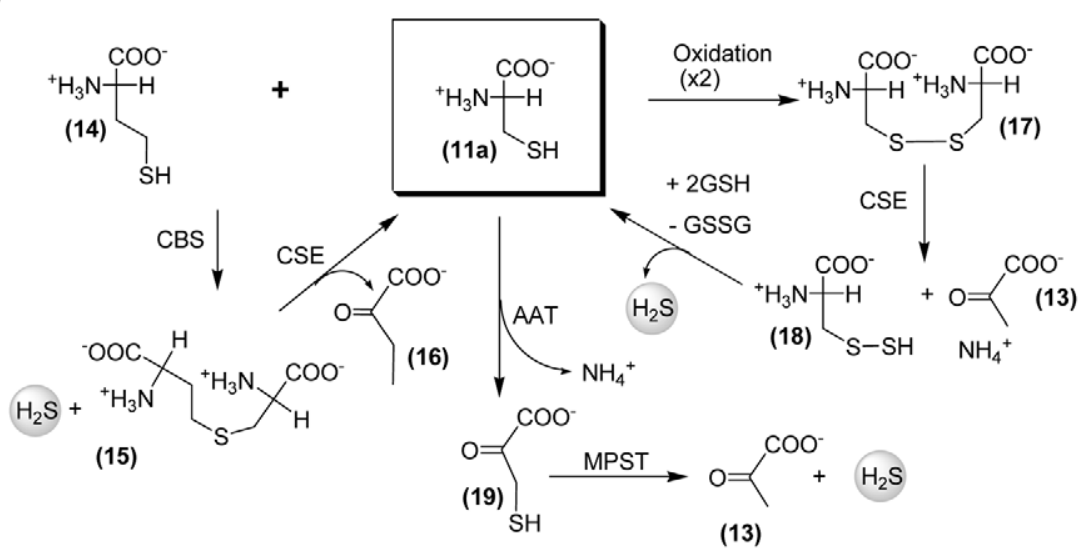

B

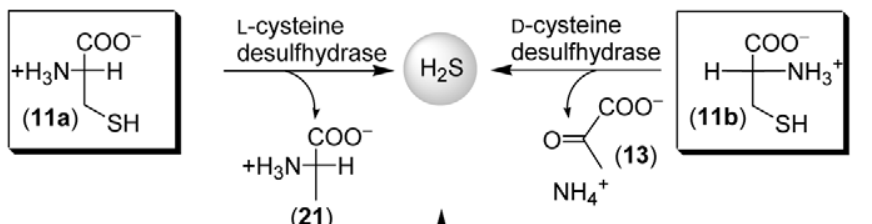

(21)
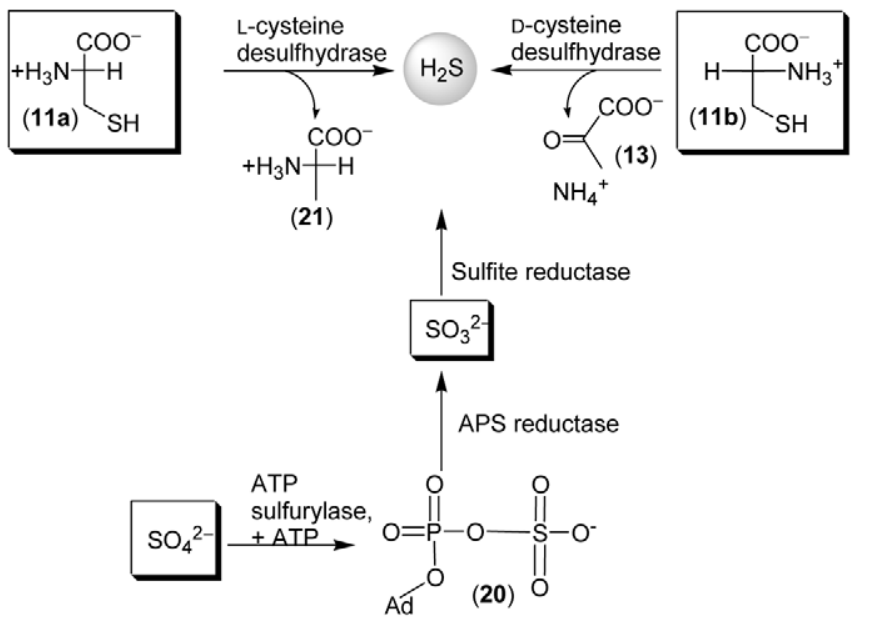

Fig. 3 Enzymatic formation of hydrogen sulfide in humans [19], [25], [32] (A) and, for comparison in plants, bacteria and yeast [33], [41] (B). The enzymatic pathways shown are only a selection and do not represent the complete hydrogen sulfide generating machinery found in biological systems. Please see text for further details. D-Cysteine (11b), homocysteine (14), cystathionine (15), $\alpha$-ketobutyrate (16), cystine (17), thiocysteine (18), 3-mercaptopyruvate (19), APS (20), alanine (21). centrations are found in the cardiovasculature, where the enzyme cystathionine $\gamma$-lyase (CSE) converts cystine to cysteine, hydrogen sulfide, ammonia and pyruvate. In addition to these cytosolic enzymes, hydrogen sulfide release from cysteine also occurs in the mitochondria, driven by the enzymes aspartate aminotransferase (AAT) and 3-mercaptopyruvate sulfur transferase (MPST), which together convert cysteine to 3-mercaptopyruvate and ammonia (AAT) and then 3-mercaptopyruvate to pyruvate and hydrogen sulfide (MPST) [25]. The three enzymecatalyzed conversions resulting in endogenous hydrogen sulfide in humans are illustrated in 0 Fig. 3A. Apart from these enzymatic pathways, there are also a range of comparably simple chemical events which may liberate hydrogen sulfide from the intracellular pool of 'labile' sulfur, for instance from the 'sulfane sulfur' pool [25]. A selection of such chemical hydrogen sulfide liberating reactions is shown in Fig. 2 and will also be discussed in more detail in connection with hydrogen sulfide release from DADS, DATS and DATTS.

We now also know that formation of hydrogen sulfide in humans is not accidental or just a side-reaction, but serves a range of important physiological functions [25]. There are several excellent recent reviews on this topic, which discuss in detail the various effects hydrogen sulfide appears to have on cellular processes [19], [23], [24], [25], [26]. We will therefore limit our discussion to a few highlights to illustrate why hydrogen sulfide, and hydrogen sulfide-generating systems in particular, must be considered as important in human health and disease.
In the brain, for instance, hydrogen sulfide contributes to proper neuronal function, and disturbed hydrogen sulfide levels have been associated with pathological states. Compared to healthy persons, hydrogen sulfide concentrations are considerably lower in the brains of Alzheimer's patients but higher in patients suffering from Down's syndrome (the gene for CBS is located on the $21^{\text {st }}$ chromosome at position 22.3) [27]. In this context, the gas appears to act as a neuromodulator, with $\mathrm{K}_{\text {ATP }}^{+}$channels the likely cellular targets of hydrogen sulfide. Needless to say, the precise biochemical mechanisms behind the effects hydrogen sulfide exerts on brain cells are still not fully understood, and a complex network of events is emerging. The latter seems to involve increases in cyclic AMP (cAMP) levels in neuronal and glial cells and hyperpolarization of neurons, probably via activation of $\mathrm{K}_{\text {ATP }}^{+}$channels [19]. Hydrogen sulfide also triggers hippocampal long-term potentiation by increasing the sensitivity of $\mathrm{N}$ methyl-D-aspartate (NMDA) receptors.

A similar picture is emerging in vascular smooth muscle cells, where hydrogen sulfide also causes the opening of $\mathrm{K}^{+}{ }_{\text {ATP }}$ channels, hyperpolarizes the cell membrane, inactivates voltage-dependent $\mathrm{Ca}^{2+}$ channels and subsequently leads to relaxation and blood vessel dilation, effects which manifest themselves in a significant reduction of blood pressure [19], [25].7 Apart from these

\footnotetext{
7 For instance, a reduction in rat arterial blood pressure of 12 to $30 \mathrm{~mm} \mathrm{Hg}$ has been reported after bolus injection of 2.8 to $14 \mu \mathrm{mol}$ hydrogen sulfide per kg body weight [28].
} 
apparent health benefits of endogenous hydrogen sulfide, a couple of other beneficial roles of this gas in the human organism have been discussed recently, including a role in immune and inflammatory diseases, such as atherosclerosis. Here, the (mostly) antioxidant properties of hydrogen sulfide, its ability to prevent leukocyte adherence and to stimulate neutrophil apoptosis come together to reduce inflammation and alleviate some of the side-effects associated with non-steroidal anti-inflammatory drugs (NSAIDs). ${ }^{8}$ Indeed, there is a whole new field of drug development emerging which focuses on hydrogen-sulfide releasing agents and their combination with NSAIDs [24]. Unfortunately, controlled hydrogen sulfide generation or release is difficult to achieve in vivo and the development of such agents poses a real challenge for chemistry. ${ }^{9}$ Nonetheless, a range of novel, water-soluble hydrogen sulfide-releasing agents have recently become available. Some of these synthetic compounds show great promise as far as controlled, slow release of hydrogen sulfide and biological activity (e.g., vasodilation) are concerned [29].

At the same time, however, a darker side of hydrogen sulfide has become apparent. As already mentioned, levels of hydrogen sulfide are increased in patients suffering from Down's syndrome. It is not clear yet if hydrogen sulfide actively contributes to the symptoms of this disorder or is just a consequence of it. At the same time, increased circulating concentrations of hydrogen sulfide have been found in patients suffering from circulatory shock, septic shock and diabetes mellitus [23]. Similarly, a 40\% increase in hydrogen sulfide synthesizing activity has been found in a carrageenan model of paw edema. Although the connection between increased levels of hydrogen sulfide on the one hand, and a range of such disorders on the other, is not yet properly understood, several attempts have been made to actually decrease levels of hydrogen sulfide, for instance, by inhibiting the hydrogen sulfide forming enzymes CBS and CSE. Since inhibitors, such as DL-propyl-argylglycine (PAG) and $\beta$-cyanoalanine (BCA), are not specific for these enzymes, there is still no clear strategy for influencing hydrogen sulfide-related diseases by inhibiting its formation, either in models or in patients. Furthermore, an inhibition of CBS or CSE may not only affect hydrogen sulfide levels, but also disturb the intracellular homeostasis of other sulfur compounds, such as cysteine, homocysteine or cystathionine.

While the formation of hydrogen sulfide in human cells, its presence in healthy organs and tissues, changes of hydrogen sulfide levels associated with various human diseases, and possible therapeutic interventions by either raising or lowering its concentrations, are now fairly well established in the literature, there are still many uncertainties as far as the biological 'chem-

\footnotetext{
${ }^{8}$ The pro- and antioxidant properties of hydrogen sulfide, and their manifestation in human health, disease and therapy are complicated and have led to a range of recent investigations, some of which even appear to contradict each other. In 2007, several reviews and perspectives have been published on this matter, in part with a firm sight on drug development (hydrogen sulfide releasing agents, inhibitors of hydrogen sulfide-generating enzymes). This literature may be considered for more in depth information on this topic.

${ }^{9}$ One may mention that the inorganic salt sodium hydrogen sulfide (NaHS) is widely used in research as a source of (exogenous) hydrogen sulfide (i.e. $\mathrm{HS}^{-}$ions which rapidly enter into equilibrium with $\mathrm{H}_{2} \mathrm{~S}$ in buffered solution). Neither NaHS, nor simple hydrogen sulfide-releasing organic molecules, however, are suitable (yet) for medical applications. Most of the organic compounds release hydrogen sulfide too fast and in an uncontrolled manner.
}

istry' of this gas is concerned. So what do we know about the chemistry of this sulfur species? At pH 7 to 8 , hydrogen sulfide is mostly present in the form of the $\mathrm{HS}^{-}$anion, which implies that we have to consider two chemically rather distinct species, one gaseous and one anionic. ${ }^{10} \mathrm{H}_{2} \mathrm{~S}$ itself is lipophilic (its solubility in lipophilic solvents is five-fold greater than in water) and it freely crosses cellular membranes [19]. $\mathrm{HS}^{-}$and $\mathrm{S}^{2-}$ bind to a wide range of transition metal ions and hence to metalloproteins. De facto, $\mathrm{S}^{2-}$ forms an essential part of various iron/sulfur clusters of redox proteins, such as in human ferredoxin, and constitutes a major source of 'acid labile' intracellular sulfur. Within this context, $\mathrm{H}_{2} \mathrm{~S}$ and its anionic forms are found in sulfhemoglobin and as 'adventitious' ligands in cytochrome $c$ oxidase. The latter is inhibited by sulfide and this event (negatively) links hydrogen sulfide to cellular energetics [23]. Hydrogen sulfide is also an inhibitor of the zinc enzyme carbonic anhydrase [30]. Indeed, interactions with metalloproteins may explain some of the biochemical events associated with hydrogen sulfide, an issue which will be discussed in more detail later on. Interestingly, metal-ligand interactions also play a decisive role in the case of 'NO and $\mathrm{CO}$, although it is now known that soluble guanylate cyclase ( $\mathrm{sGC}$ ), which provides the target for ${ }^{\circ} \mathrm{NO}$ and $\mathrm{CO}$, is not the (main) target for hydrogen sulfide.

Recent research has also uncovered a range of interactions between $\mathrm{NO}, \mathrm{CO}$ and hydrogen sulfide, not only at the level of chemical reactions ( ${ }^{\circ} \mathrm{NO}$ and $\mathrm{H}_{2} \mathrm{~S}$ react with each other to form a yet not fully characterized $S$-nitrosothiol - a chemical interaction which will be addressed in more detail later on), but also at the level of targets (all three gases compete for binding to heme, for instance in hemoglobin, which provides a common sink for the three), and at the level of formation. The latter seems to be the result of a complex interrelationship between the enzymes forming $\mathrm{NO}, \mathrm{CO}$ and $\mathrm{H}_{2} \mathrm{~S}$, i.e., nitric oxide synthases (NOS), heme oxygenase enzymes (HO-1, HO-2, HO-3) and CBS, CSE, respectively. ${ }^{11}$ The regulatory influences the three gaseous transmitters exert on each other have been summarized [32]. Considering that each of the enzymes controlling the formation of these gases is regulated by availability of substrates and various additional factors (CBS activity, for instance, is in part controlled by the allosteric activator $S$-adenosylmethionine (SAM) and is calcium and calmodulin dependent), a complex network of regulatory and control events emerges [19], [23], [31], [32]. In some ways, the latter may also explain some of the modulator activities of hydrogen sulfide, i. e., via influencing ${ }^{*} \mathrm{NO}$ or CO levels. Similarly, hydrogen sulfide metabolism on a whole impacts on a range of other important biomolecules, such as levels of homocysteine, cystathionine and cysteine, which are 'precursors' of hydrogen sulfide and hence are consumed as part of its formation. Deficiency of CSE activity in humans therefore not only results in lower levels of hydrogen sulfide, but also in cystathioninemia, an autosomal recessive inborn error with apparently no consistent clinical consequence [19]. In addition, it appears that there is a correlation between high levels of homocysteine, lower levels of hydrogen sulfide and elevated blood pressure [26].

\footnotetext{
10 The presence of hydrogen sulfide in two distinct forms distinguishes this gaseous modulator from " $\mathrm{NO}$ and $\mathrm{CO}$, both of which only occur in one, uncharged form in vivo.

$11^{-N O}$ is synthesized from L-arginine by (several isoforms) of NOS, a process also resulting in the formation of $\mathrm{L}$-citrulline; $\mathrm{CO}$ is formed together with biliverdin and iron ions from protoheme IX by one of the heme oxygenases [18], [31].
} 


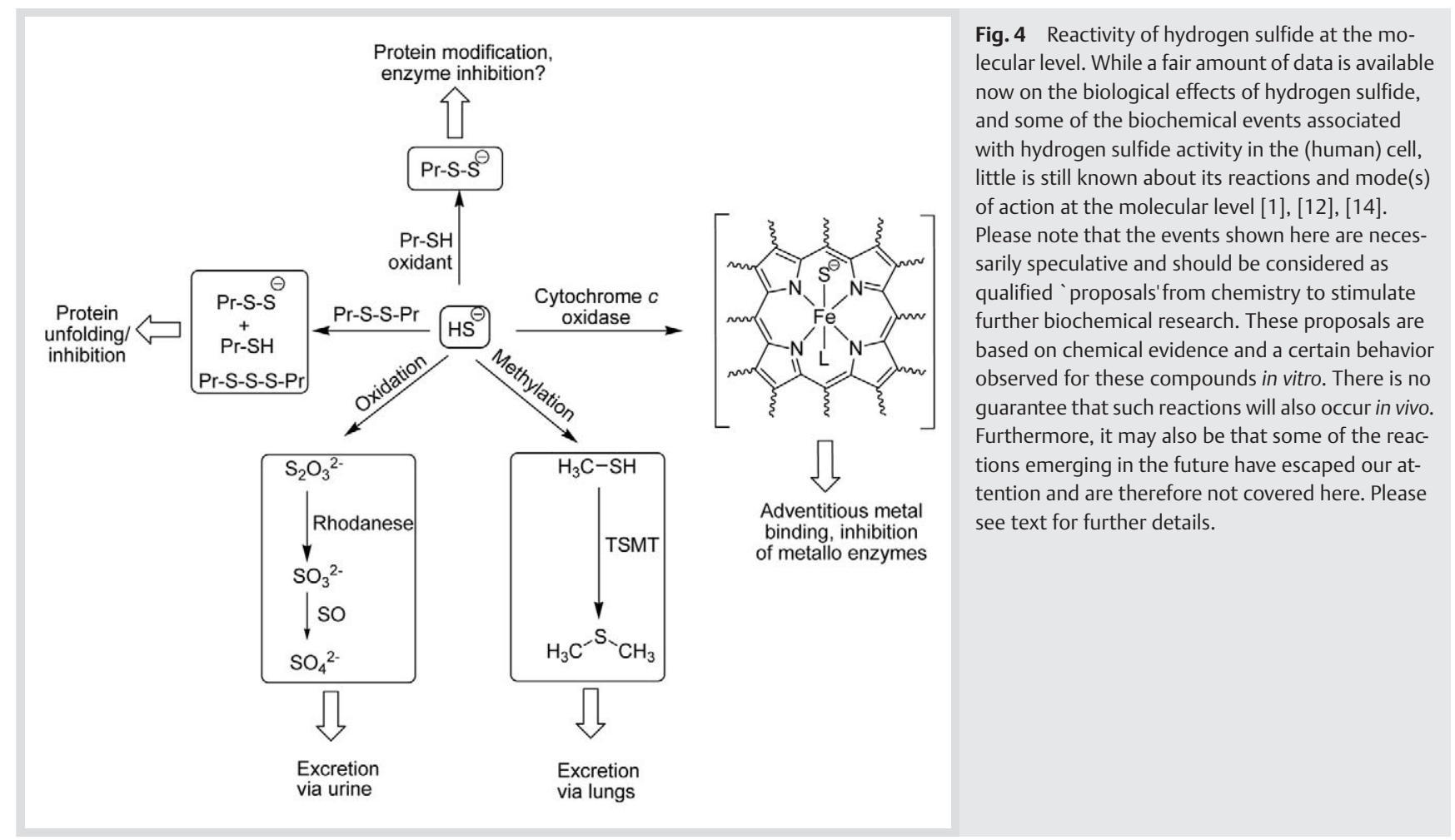

Interestingly, hydrogen sulfide is metabolized quickly in the human body. It is either oxidized to thiosulfate as part of a (spontaneous) chemical reaction (which may be catalyzed by superoxide dismutase), and further on to sulfite and sulfate. This process involves the enzymes thiosulfate-cyanide sulfurtransferase (TST, also known as rhodanese) and sulfite oxidase (SO). Alternatively, hydrogen sulfide can also be methylated to methanethiol and subsequently dimethyl sulfide by the enzyme thiol $S$-methyl transferase (TSMT). These processes are shown in $\bullet$ Fig. 4. Sulfate is the major end product of hydrogen sulfide metabolism in humans. It is excreted in urine, together with thiosulfate. Although the latter is present in urine at less than $1 \%$ of sulfate, it actually serves as a valuable biomarker for hydrogen sulfide metabolism [25].

\section{Well Established and Emerging Avenues of Hydrogen Sulfide Formation \\ $\nabla$}

After having discussed the biochemical importance of hydrogen sulfide, we will now turn our attention to the various formation pathways of hydrogen sulfide in vivo, some of which are only just emerging. Several of these avenues are summarized in $\$$ Table 2. Apart from the well established formation from cysteine, primarily catalyzed by CBS and CSE, Nature provides several other pathways leading to hydrogen sulfide. In plants, for instance, hydrogen sulfide can be formed from L-cysteine by L-cysteine desulfhydrases, as seen in Arabidopsis. Such enzymes formally 'cut out' hydrogen sulfide from cysteine, i.e., they generate hydrogen sulfide or elemental sulfur and, as second product, L-alanine ( Fig. 3B). A similar desulfhydrase activity has also been postulated for enzymes in plants using D-cysteine as substrate (e.g., in Spinacia oleracea, Chlorella fusca, Cucurbita pepo, Cucumis sativus, Nicotiana tabacum). Processing of D-cysteine by these enzymes leads to hydrogen sulfide, ammonia and pyruvate [33]. Sulfur transferases, on the other hand, are able to (formally) transfer sulfur 'atoms' between molecules, and may release hydrogen sulfide (and elemental sulfur) in the process (for instance, MPST, which converts 3-mercaptopyruvate into pyruvate and hydrogen sulfide, see above).

A quite different avenue leading to hydrogen sulfide is also found in plants, which employ sulfite reductases in their plastides able to convert $\mathrm{SO}_{3}{ }^{2-}$ to $\mathrm{HS}^{-}$in a process formally requiring six electrons ( Fig. 3b). ${ }^{12}$ In these plants, hydrogen sulfide derived from sulfite is primarily used to form cysteine. Interestingly, it may also serve as part of a plant defense system called 'sulfur-induced resistance' (SIR) employed, for instance, against fungal infections (this concept has been evaluated recently for rape plants (Brassica napus)) [33]. One should mention here that hydrogen sulfide has long been considered as possible pesticide [35], although reports on its efficiency are somewhat conflicting [36]. As far as the impact of SIR on human health is concerned, it has been estimated that plants only generate around $2-3 \mathrm{~kg}$ of $\mathrm{H}_{2} \mathrm{~S}$ per hectare per year, which is obviously not significant to pose a risk to human well-being.

Like plants, bacteria also provide several pathways for hydrogen sulfide synthesis. Escherichia coli, for instance, exhibits a pyridoxal 5'-phosphate (PLP) containing D-cysteine desulfhydrase enzyme. Numerous bacteria living in human (and other) intestines are able to produce hydrogen sulfide by fermentation of sulfur-containing amino acids, reduction of sulfate and sulfite and through intestinal sulfomucin metabolism [37]. In fact, the activity of sulfate-reducing bacteria (SRB) and related organisms

\footnotetext{
12 Sulfite reductases often work hand in hand with enzymes reducing readily available sulfate $\left(\mathrm{SO}_{4}{ }^{2-}\right)$ to sulfite $\left(\mathrm{SO}_{3}{ }^{2-}\right)$ [34]. This process involves the initial formation of adenosine $5^{\prime}$-phosphosulfate (APS) from sulfate, an adenylation reaction catalyzed by ATP sulfurylase (ATPS) enzymes. APS is then reduced to sulfite by APS reductase enzymes, consuming GSH and also releasing adenosine $5^{\prime}$-phosphate in the process. Please note that the overall reduction of $\mathrm{SO}_{4}{ }^{2-}$ to hydrogen sulfide formally consumes a total of eight electrons.
} 
Table 2 A brief overview of the various enzymatic and chemical transformation pathways resulting in the formation of hydrogen sulfide in vivo. Please note that this table is necessarily incomplete and speculative at times.

\begin{tabular}{|c|c|c|c|c|c|}
\hline Pathway & $\begin{array}{l}\text { Source of hydrogen } \\
\text { sulfide }\end{array}$ & Enzymes involved & Products & $\begin{array}{l}\text { Occurrence } \\
\text { (examples only) }\end{array}$ & References \\
\hline $\begin{array}{l}\text { Cystathionine } \beta \text {-syn- } \\
\text { thase (CBS) enzymatic } \\
\text { pathway }\end{array}$ & $\begin{array}{l}\text { L-cysteine and L-homo- } \\
\text { cysteine }\end{array}$ & CBS & $\begin{array}{l}\text { hydrogen sulfide, cys- } \\
\text { tathionine }\end{array}$ & $\begin{array}{l}\text { mammals, humans } \\
\text { (primarily in brain) }\end{array}$ & $\begin{array}{l}{[19],[23],} \\
{[27]}\end{array}$ \\
\hline $\begin{array}{l}\text { Cystathionine } \gamma \text {-lyase } \\
\text { (CSE) enzymatic path- } \\
\text { way }\end{array}$ & cystine & CSE & $\begin{array}{l}\text { hydrogen sulfide, am- } \\
\text { monia, pyruvate (via } \\
\text { thiocysteine) }\end{array}$ & $\begin{array}{l}\text { mammals, humans } \\
\text { (primarily in smooth } \\
\text { muscle cells) }\end{array}$ & {$[25],[32]$} \\
\hline $\begin{array}{l}\text { Mitochondrial 3-mer- } \\
\text { captopyruvate sulfur } \\
\text { transferase (MPST) } \\
\text { pathway }\end{array}$ & $\begin{array}{l}\text { cysteine, 3-mercapto- } \\
\text { pyruvate }\end{array}$ & $\begin{array}{l}\text { aspartate amino trans- } \\
\text { ferase, MPST }\end{array}$ & $\begin{array}{l}\text { hydrogen sulfide, am- } \\
\text { monia, pyruvate }\end{array}$ & $\begin{array}{l}\text { mitochondria of } \\
\text { mammals, humans }\end{array}$ & {$[25]$} \\
\hline $\begin{array}{l}\text { I-Cysteine desulfhy- } \\
\text { drase pathway }\end{array}$ & L-cysteine & $\begin{array}{l}\text { L-cysteine desulfhy- } \\
\text { drase }\end{array}$ & $\begin{array}{l}\text { hydrogen sulfide, t-ala- } \\
\text { nine }\end{array}$ & $\begin{array}{l}\text { plants } \\
\text { (e.g., Arabidopsis) }\end{array}$ & [33] \\
\hline $\begin{array}{l}\text { D-Cysteine desulfhy- } \\
\text { drase pathway }\end{array}$ & D-cysteine & $\begin{array}{l}\text { D-cysteine desulfhy- } \\
\text { drase }\end{array}$ & $\begin{array}{l}\text { hydrogen sulfide, am- } \\
\text { monia, pyruvate }\end{array}$ & $\begin{array}{l}\text { plants (e. g., Spinacia } \\
\text { oleracea, Nicotiana ta- } \\
\text { bacum), bacteria } \\
\text { (e.g., E. coli) }\end{array}$ & [33], [37] \\
\hline Thiosulfate reduction & $\mathrm{S}_{2} \mathrm{O}_{3}{ }^{2-}, \mathrm{GSH}$ & thiosulfate reductase & $\begin{array}{l}\text { hydrogen sulfide, } \\
\text { GSSG }\end{array}$ & yeast & [46] \\
\hline $\begin{array}{l}\text { Sulfite reduction path- } \\
\text { way }\end{array}$ & $\mathrm{SO}_{4}{ }^{2-}, \mathrm{SO}_{3}{ }^{2-}$ & $\begin{array}{l}\text { ATP sulfurylase, APS } \\
\text { reductase, sulfite re- } \\
\text { ductase }\end{array}$ & Hydrogen sulfide & $\begin{array}{l}\text { various plants (e. g., } \\
\text { Brassica napus), sulfate } \\
\text { reducing bacteria } \\
\text { (SRB), yeasts }\end{array}$ & [33], [34] \\
\hline
\end{tabular}

in the gut seems to result in hydrogen sulfide concentrations of between 1 and 2.4 millimolar in the lumen of the human large intestine. ${ }^{13}$ Interestingly, the human intestines are able to deal with such rather large amounts of hydrogen sulfide, either by the familiar 'gone with the wind' approach or by oxidizing/metabolizing it to sulfate and/or (di-)methyl sulfide. $\mathrm{H}_{2} \mathrm{~S}$ formed by SRB therefore does not seem to constitute a major risk to human health. Although $\mathrm{H}_{2} \mathrm{~S}$ readily crosses cellular membranes, it is unlikely that it can enter the body through the intestines unhindered and subsequently poison the organism. Whether or not elevated concentrations of hydrogen sulfide in the lumen may cause more subtle damage via its recently discovered modulator properties is, however, still an interesting matter of ongoing debate and research. In this context, hydrogen sulfide in the gut has been linked, for instance, to ulcerative colitis [38]. In any case, the matter of SRB and hydrogen sulfide formation in the human digestive system is of potential interest in the context of another area of drug research, which deals with unpleasant but perhaps less life-threatening issues. Here, the aim is to reduce the buildup and excretion of $\mathrm{H}_{2} \mathrm{~S}$ from the human intestines, and the formation of $\mathrm{H}_{2} \mathrm{~S}$ in the mouth (bacteria in the tongue biofilm also generate $\mathrm{H}_{2} \mathrm{~S}$ and hence oral malodor) [40].

Finally, various yeasts, such as wine yeasts, Saccharomyces cervisiea, also have the capability to generate $\mathrm{H}_{2} \mathrm{~S}$ from sulfate and sulfite by employing sulfite reductase enzymes [41]. Although not a major issue in the context of human health, this avenue leading to hydrogen sulfide may have some commercial implications since grape juices tend to contain sulfate - and sulfite is sometimes used in this context as a preservative.

\footnotetext{
${ }^{13}$ In a series of rather delicate experiments, hydrogen sulfide formation in the gut and in faeces has recently been investigated [38], [39]. Within this context, one needs to bear in mind that hydrogen sulfide formed in the gut may not simply diffuse into the (human) body. It may also be passed or end up as (inert) sulfide anions bound to metal ions in the faeces. Indeed, the use of zinc, iron and bismuth ions has been suggested to reduce the amounts of $\mathrm{H}_{2} \mathrm{~S}$ in flatus.
}

After this brief and necessarily incomplete glance at the various enzymatic formation pathways of hydrogen sulfide, we will now turn out attention to some of the rather interesting and biologically relevant chemical pathways leading up to hydrogen sulfide (see also Fig. 2). Many of these pathways are just emerging and are still somewhat speculative at this time, especially as far as their relevance in vivo is concerned. Nonetheless, the chemistry behind them provides a range of interesting new perspectives, especially in the field of nutrition, medical plants and cellular modulation via hydrogen sulfide and other reactive sulfur species.

To begin with, we will need to consider the perhaps most aggressive of chemical transformations, namely thermal decomposition of organosulfur compounds, including cysteine, which decomposes thermally to $\mathrm{H}_{2} \mathrm{~S}, \mathrm{NH}_{3}, \mathrm{CO}_{2}$ and acetaldehyde $\left(\mathrm{CH}_{3} \mathrm{CHO}\right)$. Although such processes are impossible inside the human body, they may occur during food preparation and hence provide hydrogen sulfide, most probably $\mathrm{HS}^{-}$and metal-bond $\mathrm{S}^{2-}$, via the oral route. This chemistry has been mentioned in Dipak Das' editorial focus on a paper describing a positive correlation between hydrogen sulfide and $S$-allylcysteine (SAC), which itself, interestingly enough, must release hydrogen sulfide by a rather different chemical route in vivo [2], [17]. Nonetheless, fried garlic and onions, but also processed Parkia speciosa seeds and even lychee fruits may release hydrogen sulfide once heated up [3], [42], [43]. Unlike plants employing SIR, however, hydrogen sulfide release from these plants must be seen as artificial.

Artificial release of hydrogen sulfide due to cooking, frying etc., however, may not be the only avenue converting the organic sulfur compounds contained within foodstuffs into hydrogen sulfide. As mentioned in the introduction, a series of recent studies has shown that significant amounts of hydrogen sulfide may also be released from organosulfur compounds under mild conditions and in the absence of enzymes, yet still as part of normal physiological processes. Although such reactions appear to occur spontaneously, they may well be under cellular control. They 
may, for instance, be triggered by intracellular glutathione (GSH) - and hence provide a rather interesting degree of specificity and selectivity. We will now consider these mechanisms in more detail (see also $\odot$ Fig. 2). Please note that this discussion is in part based on chemical and in vitro evidence and may ultimately not necessarily reflect processes taking part in vivo.

Hydrogen sulfide release from tri-, tetra- and higher polysulfides (generally: $\mathrm{RS}_{\mathrm{x}} \mathrm{R}, \mathrm{x} \geq 3$ ) appears to be a fairly straight forward process ( $\bullet$ Fig. 2) [14]. A series of nucleophilic attacks at the sulfur-sulfur bonds of these polysulfides, for instance by GSH, results in the release of $\mathrm{S}^{2-}\left(\right.$ or $\mathrm{S}_{\mathrm{x}}{ }^{2-}$ ) and the formation of either mixed disulfides (RSSG) or RSH and GSSG..$^{14}$ Thiol/disulfide exchange reactions are, in principle, possible with all di- and polysulfides, regardless of the chemical nature of the R group. For instance, they have been postulated for the antibiotic varacin (from Lissoclinum vareau) and DATS [44]. In the case of disulfides, however, the thiol/disulfide exchange reaction 'only' liberates a thiol (RSH), and no sulfide ( $\left.\mathrm{S}^{2-}\right)$ is formed (see below).

As an interesting twist, in case the polysulfide has a sulfur chain length of four or more, $S_{x}{ }^{2-}$ species (with $x \geq 2$ ) may also be formed besides $\mathrm{S}^{2-}$ as part of such exchange reactions. These inorganic polysulfide ions exhibit a rather 'murky' chemistry and biochemistry [14]. In principle, they could act as reducing agents, for instance by reducing disulfide bonds in proteins (PrSSPr) to form thiols (PrSH), perthiols (PrSSH) and hydropolysulfides $\left(\operatorname{PrS}_{x} \mathrm{H}, \mathrm{x} \geq 3\right)$. Alternatively, they could also fully reduce the protein (PrSH formation), forming other, more oxidized polysulfide ions, such as $\mathrm{S}_{2 \mathrm{x}}{ }^{2-}$, in the process. On the other hand, $\mathrm{S}_{\mathrm{x}}{ }^{2-}$ may still react as oxidant, for instance, by oxidizing protein thiols to disulfides and releasing hydrogen sulfide in the process. In addition, $\mathrm{S}_{\mathrm{x}}{ }^{2-}$ species are also likely to interact strongly with metal ions, which may endow them with a biological activity on their own. In fact, $\mathrm{S}_{\mathrm{x}}{ }^{2-}$ species may be considerably more reactive than hydrogen sulfide itself. This area of 'bio-inorganic' sulfide chemistry has clearly not been fully explored yet. Considering that DATTS may release $\mathrm{S}_{2}{ }^{2-}$, a focus just on hydrogen sulfide $\left(\mathrm{S}^{2-}\right)$ may be too narrow at this time.

Amazingly, the recent excitement in garlic research and hydrogen sulfide-mediated vasoactivity (which has been associated with possible cardioprotection) has not come (exclusively) from the 'usual' suspects with regard to hydrogen sulfide release, i.e., DATS and DATTS, but has also been linked to two rather unsuspected molecules, namely the disulfide DADS and the monosulfide $S$-allylcysteine, which apparently are also able to increase hydrogen sulfide levels in certain cells [15], [17]. From a chemical perspective, these findings are particularly intriguing, since hydrogen sulfide release from mono- (RSR) and disulfides (RSSR) under physiological conditions is less obvious.

Let's consider the disulfide first. Here, we generally find two electrophilic centers suitable for attack by a nucleophile, such as GSH (see $\odot$ Fig. 2). The first one clearly is the sulfur-sulfur bond with a bond energy of $293 \mathrm{~kJ} \mathrm{~mol}^{-1}$ (such values vary, of course, depending on the R groups present in RSSR). Nonetheless, the carbon-sulfur bond may also be attacked, since it is energetically similar to the sulfur-sulfur bond $\left(289 \mathrm{~kJ} \mathrm{~mol}^{-1}\right) .{ }^{15} \mathrm{Nu}-$ cleophilic attack by GSH at the $\alpha$-carbon atom of the disulfide

\footnotetext{
${ }_{14}$ The precise outcome of these thiol/disulfide exchange reactions depends on the redox potentials of RSH and GSH, the potentials of their oxidized forms, and the concentrations of reaction partners involved.

${ }^{15}$ In comparison, the carbon-carbon bond is considerably more stable (around $348 \mathrm{~kJ} \mathrm{~mol}^{-1}$ ).
}

(RSSR) results in the formation of a sulfide (RSG) and a perthiol RSSH (which is deprotonated to RSS-). The perthiol is a chemically rather reactive compound. Like some of the $\mathrm{S}_{\mathrm{x}}{ }^{2-}$ species, RSSH may act as reductant, for instance, reducing $\mathrm{O}_{2}$ to $\mathrm{O}_{2}{ }^{-{ }^{-}}$as part of a (probably metal-catalyzed) reaction, which also results in a polysulfide and may trigger an intracellular oxidative burst. On the other hand, RSSH may still be reduced further by GSH, a reaction which ultimately leads to the formation of GSSG and RSH and liberates one equivalent of hydrogen sulfide from RSSH (and hence from RSSR). Importantly, this reaction may occur in principle with any disulfide, assuming the $\mathrm{R}$ group exerts an electronic (and steric) effect which favors attack at the $\alpha$-carbon. This consideration applies to DADS from garlic, but also to dialkyl disulfides which are found, for instance, in onions. It does not seem to apply, however, to GSSG, although this may be a matter for further investigations.

In contrast, another mechanism for hydrogen sulfide release from disulfides is fairly specific for diallyl disulfide found in garlic. This chemical reaction pathway is initiated by nucleophilic attack (for instance of GSH) at the olefinic carbon of DADS, causing double bond migration and release of allyl perthiol (RSSH), which can react further to release hydrogen sulfide. As above, the second product is a mixed sulfide (RSG), yet in contrast to the $\alpha$-carbon attack pathway, the glutathionyl moiety is now bound to the olefinic carbon, i.e., the $\gamma$-carbon, not the $\alpha$-carbon. ${ }^{16}$

\section{S-Allylcysteine}

$\nabla$

While these hydrogen sulfide release mechanisms provide a plausible explanation for the vasoactivity observed for DADS in the studies by Kraus and colleagues [16], they may not explain the chemistry behind $S$-allylcysteine. Although the latter may also be attacked at the $\alpha$-carbon or olefinic carbon, such reactions would liberate a thiol, not a perthiol, and it is difficult (but not impossible) to conceive how hydrogen sulfide could subsequently be released. ${ }^{17}$ Indeed, Kraus and colleagues did not observe an effect with diallyl monosulfide (DAS) in their study, indicating that a simple hydrogen sulfide release from the monosulfide may not occur (or at least not in amounts able to trigger an observable effect).

Not surprisingly, perhaps, Zhu and colleagues also do not directly speculate about hydrogen sulfide release from $S$-allylcysteine in their own test system. They rather consider if S-allylcysteine may have "upregulated expression of CSE" or may have led to an "increase in efficiency of CSE, since SAC increased the availability of CSE substrates" [17].

If and how $S$-allylcysteine may be a source of hydrogen sulfide is a matter of qualified speculation, for which we need to revisit the chemistry of CBS, CSE and related (PLP-dependent) enzymes. Here, we will follow up four interesting ideas, namely chemical release of cysteine from $S$-allylcysteine, enzymatic release of

\footnotetext{
${ }^{16}$ We have used GSH here as a representative example of intracellular thiolbased nucleophiles. This does not imply, of course, that this chemistry is limited to GSH. In fact, any thiol with appropriate nucleophilicity may participate in this chemistry, including thiols present in proteins and enzymes.

${ }^{17}$ Here, we are somewhat cautious not to refer too bluntly to a second nucleophilic attack of GSH at one of the two relevant carbons of RSH (e.g. allyl mercaptan). Such a reaction in theory could indeed result in the formation of RSG and the release of hydrogen sulfide - although chemists may have some reservations with regard to such a process.
} 
cysteine, direct (or indirect) release of hydrogen sulfide from $S$ allylcysteine and the possibility of an alliinase-like enzymatic chemistry in humans. At this time all four possibilities must be treated as speculative - and hence with some caution.

First of all, it may be possible that $S$-allylcysteine is a source of cysteine, and hence feeds into the human metabolic pathways which (also) generate hydrogen sulfide. This idea forms part of the considerations by Zhu and colleagues regarding the availability of CSE substrates. Indeed, one may envisage chemical or enzymatic processes converting $S$-allylcysteine to cysteine [17]. Attack of GSH at the $\alpha$-carbon or olefinic carbon of the allyl group, for instance, may liberate cysteine in a process which also forms S-allylglutathione ( Fig. 2). Such a reaction would, however, consume one equivalent GSH per equivalent of cysteine released. It is unclear why such a reaction should be particularly beneficial to the human cell, since there is no net gain in thiols. Indeed, the cell may as well release cysteine from GSH in the first instance, for instance by hydrolysis.

We will therefore consider the second alternative, i.e., an enzymatic process liberating cysteine from $S$-allylcysteine. As illustrated in $\bullet$ Fig. 3A, CBS 'condenses' two thiols (cysteine and homocysteine) to a monosulfide (cystathionine), releasing hydrogen sulfide in the process. In contrast, CSE is a 'cutter' with a distinct C-S lyase activity: it cleaves a carbon-sulfur bond in monosulfides (cystathionine) and disulfides (cystine) with the formation of a thiol (cysteine) and perthiol (thiocysteine), respectively (the additional products of this lyase reaction being ammonia, $\alpha$ ketobutyrate (in case of cystathionine) and pyruvate (in case of cystine)). Thiocysteine formed from cystine as part of this process may then react further to release hydrogen sulfide. A similar breakdown of $S$-allylcysteine, either catalyzed by CSE or another C-S lyase may therefore liberate cysteine (or, alternatively, allyl mercaptan, see below) without consuming cellular thiols ( Fig. 2). If and how such a reaction may occur in humans, and which by-products may be formed, is still unclear. We must remember, however, that the oxidized form of $S$-allylcysteine, i.e., $S$-allylcysteine sulfoxide (alliin), is a precursor in allicin synthesis, which is indeed cleaved by the (plant) C-S-lyase alliinase to form allyl sulfenic acid, ammonia and pyruvate [1]. Although $S$ allylcysteine is clearly not a substrate for alliinase, it is possible that this compound is cleaved enzymatically by a similar C-S lyase enzyme. Then again, the formation of $S$-allylcysteine from allicin (and its follow-on products) actually consumes cysteine in the first instance, and the benefit of subsequent cysteine liberation from $S$-allylcysteine is not quite apparent. In any case, considering the high amounts of cysteine present in human cells, such a process may not solely explain the cardioprotective effects observed.

It may, however, be possible that allyl mercaptan (together with ammonia and pyruvate) is formed from $S$-allylcysteine instead ( Fig. 2). The implications of this third pathway are rather interesting. Allyl mercaptan is readily oxidized to form mixed disulfides, such as S-allylmercaptoglutathione, or DADS. Importantly, formation of these disulfides from allyl mercaptan goes hand in hand with the reduction of intracellular disulfides, i.e., there is no 'loss', but actually an overall gain in cysteine thiol residues, which in itself may be beneficial to the cell. Due to the presence of the allyl group in the disulfides formed, such disulfides are also fairly reactive, and as shown by Kraus and colleagues for DADS, may readily release hydrogen sulfide by a simple chemical mechanism involving a perthiol. It is therefore feasible that $S$-allylcysteine is converted enzymatically to allyl mercap- tan, which in a reaction beneficial to the cell is (spontaneously) oxidized to DADS (or a mixed disulfide), which in turn is then attacked by GSH to release a perthiol and subsequently hydrogen sulfide. Although still speculative at this time, this pathway would lead rather directly from $S$-allylcysteine to hydrogen sulfide without the need of intermediate cysteine formation; it would also explain the requirement for a C-S lyase enzyme as part of S-allylcysteine (bio)chemistry.

We will now consider the final and probably most speculative option, which we will carefully phrase as a question only. Is $S$-allylcysteine oxidized in the human body to alliin which, in turn, is processed to allicin by human enzymes? The answer to this question would obviously have significant implications for our current understanding of C-S lyase activity and associated sulfoxide-to-thiosulfinate conversions in humans. This pathway is particularly attractive since it would endow $S$-allylcysteine with a distinct chemistry and associated biochemical activity, not only in plants, but also in humans. Unlike the release of cysteine, which appears to be of rather limited significance in cells rich in cysteine- and cysteine-containing peptides and proteins, anyway, the formation of allicin may trigger a range of chemical and biochemical processes which may have a significant impact on intracellular events. For instance, it may explain changes in levels and activity of CSE, changes which may ultimately provide the missing link between $S$-allylcysteine, hydrogen sulfide and cardioprotection.

Within this context, one is tempted to point out that the postulation of a novel enzymatic activity in humans, such as an alliinase-like activity, which has previously only associated with plants and bacteria, is not foolish. Only recently, a suspected nitrate reductase activity apparently present in human cells has been discussed as part of a novel pathway generating ${ }^{\circ} \mathrm{NO}$ in humans [45].

\section{The Labile Sulfur Pool}

\section{$\nabla$}

In principle, hydrogen sulfide may also be formed inside the human cell by a range of other, perhaps less obvious chemical avenues. Within this context, one source of hydrogen sulfide is the 'labile sulfur pool' in each cell. Here, we find various metalloproteins which contain $\mathrm{S}^{2-}$ ions as part of metal/sulfur clusters, such as iron/sulfur clusters. Changes in $\mathrm{pH}$, such as acidification, may result in the release of this type of 'inorganic sulfur' in the form of $\mathrm{S}^{2-}$ ions which would equilibrate to $\mathrm{HS}^{-}$and $\mathrm{H}_{2} \mathrm{~S}$. Some organs, such as the heart, liver and brain, indeed contain significant amounts of acid-labile sulfur, with ratios of acid-labile to total sulfur of almost $1: 1$ reported in the rat heart. Lungs and muscle, in contrast, contain considerably less acid-labile sulfur [46]. Another source of readily available hydrogen sulfide are perthiols and hydropolysulfides (see above), which form part of the intracellular pool of 'active reduced sulfur' (sulfane sulfur) and hence occupy a prominent role in intracellular sulfur chemistry. Although they are highly nucleophilic, perthiols (RSSH) are also readily attacked by other nucleophiles, such as GSH, resulting in a disulfide (RSSG) and hydrogen sulfide release. Interestingly, within a biochemical context, perthiols are not rare or exotic molecules: They are formed by various avenues in vivo, and the most apparent ones will be considered here briefly. First of all, thiocysteine is formed from cystine in a reaction catalyzed by CSE, the initial step in an important formation pathway of endogenous hydrogen sulfide which we have already discussed 
above in some detail (see also $\bullet$ Fig. 3a). Secondly, perthiols and hydropolysulfides are formed as part of the reaction of polysulfides with thiols (see above). And finally, the reaction of a thiol with elemental sulfur results in the formation of a perthiol or hydropolysulfide. Since elemental sulfur may also form part of the intracellular labile sulfur pool, its involvement in perthiol and hydrogen sulfide formation may be of some importance.

\section{The Chemistry of Hydrogen Sulfide: Possible Modes of Action}

In the final part of this Perspective, we will briefly consider the chemistry which hydrogen sulfide may engage in once formed inside human cells ( $\bullet$ Fig. 4) [14]. These considerations are currently particularly important, since the exact mode(s) of action of this gasotransmitter at the molecular level are still not fully understood. Nonetheless, the following discussion is speculative in part as far as the in vivo situation is concerned - and therefore needs to be treated with some caution.

As already mentioned, $\mathrm{HS}^{-}$and $\mathrm{S}^{2-}$ are excellent ligands for various (transition) metal ions. As such, they may bind to and (reversibly) inhibit a range of metalloproteins. Indeed, this action of hydrogen sulfide manifests itself in the presence of iron and zinc enzymes, such as cytochrome $c$ oxidase and carbonic anhydrase. Although hydrogen sulfide does not interact with sGC, binding to metalloproteins brings this gasotransmitter in line with ${ }^{\circ} \mathrm{NO}$ and $\mathrm{CO}$, both of which exert their biological activity by interacting with metalloproteins.

Apart from binding to metal centers, hydrogen sulfide is also an excellent reducing agent. As such, it may act either as pro- or antioxidant. For instance, it may reduce $\mathrm{O}_{2}$ to $\mathrm{O}_{2}{ }^{--}$, thereby triggering a pro-oxidant cascade of reactive oxygen species. Or it may act as an antioxidant reducing agent, for instance, by reducing and hence removing peroxynitrite. Interestingly, the redox chemistry of hydrogen sulfide is not limited to such simple redox transformations: When placed in the context of intracellular sulfur chemistry, it actually turns out to be rather complex. First of all, hydrogen sulfide may insert into and reduce disulfide bonds in proteins and enzymes, a process which may result in a significant disturbance of the protein's structure and hence its function and activity. At the same time, this type of reduction would necessarily also result in the formation of a protein-bound perthiol, which in itself must be considered as a highly reactive - and not always benign - sulfur species (see $\mathrm{O}_{2}{ }^{--}$formation).

Furthermore, hydrogen sulfide may attack thiols in proteins and enzymes in a reaction which forms perthiols and necessarily also requires the presence of an oxidizing agent. As above, such a reaction could obviously significantly change the function and activity of the protein or enzyme involved, particularly if the thiolto-perthiol conversion occurs at an active site cysteine residue. Once formed, the perthiol, and with it the protein affected, may exhibit a chemistry on its own, which may deviate considerably from the one of the unmodified protein.

And finally, one should emphasize once more the intricate relationship which exists between 'NO and hydrogen sulfide. Apart from possible shared cellular targets and a suspected mutual regulation at the level of each others generation, the direct interaction of these two molecules results in an interesting chemistry with biochemical significance. Here, the chemical reaction of 'NO and hydrogen sulfide to a (hitherto unidentified and probably chemically unstable) $S$-nitrosothiol has three distinct conse- quences. First of all, this reaction consumes 'NO and is therefore able to 'regulate' 'NO levels in the cell. Secondly, the reaction regulates hydrogen sulfide levels. And thirdly, this reaction may initiate the formation of a cascade of reactive nitrogen and/or reactive sulfur species. Without intending to speculate excessively, one may well envisage the formation of nitrogen- and sulfurcentered radicals and various nitrogen- and sulfur-based oxides, at least from a chemical point of view [47], [48], [49], [50], [51]. Importantly, the notion that a chemical reaction between 'NO and hydrogen sulfide may control levels of the two transmitters and serve as an opening to a follow-on chemistry is speculative yet not without precedence. The reaction of ${ }^{\cdot} \mathrm{NO}$ and $\mathrm{O}_{2}{ }^{--}$to peroxynitrite $\left(\mathrm{ONOO}^{-}\right)$, for instance, fulfils precisely these criteria: This reaction controls levels of the two radicals and provides the entry point to an extensive in vivo chemistry based on $\mathrm{ONOO}^{-}$and its follow-on products. If an analogous chemistry exists for the $S$-nitrosothiol formed from 'NO and hydrogen sulfide, and which impact this chemistry may have on the cell, is unclear at this time. Besides the various other interactions hydrogen sulfide is suspected to undergo with biomolecules, the connection with ${ }^{\mathrm{NO}}$ may therefore provide a fertile ground for a number of important 'bioinorganic' discoveries in the future.

\section{Outlook}

$\nabla$

The previous sections have provided a glimpse at the emerging chemistry and biochemistry of hydrogen sulfide, its possible formation pathways and transformations in vivo, modes of biochemical action and implications for human health and disease. Many aspects of this (bio)chemistry have only become apparent during the last couple of years, and many questions still remain unanswered. In fact, there are also a couple of questions which still need to be raised first.

Our first question relates to the presence of hydrogen sulfide donors in natural foodstuffs, such as garlic, onions, Shiitake mushrooms, certain beans and even lychees. Future research will have to take a closer look at these various natural sources of hydrogen sulfide, since they may provide consumers with an unexpected, yet important source of exogenous hydrogen sulfide. Such a natural 'hydrogen sulfide therapy' may well result in some of the health benefits associated with hydrogen sulfide, but, as we also know now, may also cause some damaging effects.

Within this context, there are also open questions regarding the extent to which natural foodstuffs are able to contribute to hydrogen sulfide levels in human plasma. In essence, consumption of vegetables containing hydrogen sulfide-releasing substances is limited: Not many people continuously chew on a clove of garlic or eat kilograms of onions every day. Ultimately, the amount of hydrogen sulfide entering the human body via the diet may therefore be small compared to the amount of hydrogen sulfide produced enzymatically by CBS and CSE.

In addition, the pharmacokinetic profile of hydrogen sulfide-releasing foodstuffs and associated hydrogen sulfide formation need to be studied in more detail. For instance, we need to understand which levels of hydrogen sulfide-releasing substances - and, subsequently, dietary-derived hydrogen sulfide itself may be present in the human blood stream at a given time. Here, DATS concentrations of up to $31 \mu \mathrm{M}$ have been achieved in rat plasma, albeit after injection of this hydrogen sulfide-releasing compound, and not after its ingestion [52]. Furthermore, it needs to be shown if hydrogen sulfide is released in form of a 
'hydrogen sulfide burst' after an appropriate meal, or if there is a more gentle appearance and disappearance of hydrogen sulfide over time? Such questions clearly are important when considering the biochemical and potential 'therapeutic' impact of dietary hydrogen sulfide sources, such as garlic, onions, leeks and certain mushrooms.

Not surprisingly, more research is required to clarify these matters. At the same time, hydrogen sulfide and its precursors may not occur in the raw plant or mushroom. Processing of such foodstuffs, i.e., chopping, heating, cooking and frying, appears to control the sulfur chemistry which is ultimately 'consumed'. Further studies are therefore required to consider at which point the relevant natural products actually turn into hydrogen sulfide donors, rather than simply being sources of organosulfur compounds, such as allicin or lenthionine.

Another major area of research is emerging in the context of drug development. Here, we find several approaches designed to control intracellular levels of hydrogen sulfide. On the one end, hydrogen sulfide-releasing drugs, possibly coupled to NSAIDs, form a major line of investigation. Since hydrogen sulfide release from such agents needs to be controlled tightly in the complex environment of the human body (excess hydrogen sulfide is toxic!), the development of such drugs poses a massive challenge for chemists, and only a few leads are available to date [24], [29]. At the other end, there are also attempts to lower the levels of hydrogen sulfide, for instance, by inhibiting CBS and CSE. Then again, currently available inhibitors of these enzymes are marred with problems, such as low selectivity for CBS or CSE. The development of specific CBS inhibitors (e.g., for the treatment of Down's syndrome) or CSE inhibitors is still a fruitful, yet difficult area of research.

Ultimately, many aspects of hydrogen sulfide biochemistry still need to be resolved. At the molecular level, in particular, many questions remain as to how $\mathrm{H}_{2} \mathrm{~S}, \mathrm{HS}^{-}$or $\mathrm{S}^{2-}$ are able to exhibit a distinct chemistry and biochemistry when surrounded by a pool of other thiols, some of which may even be more reactive (such as perthiols, possibly allyl mercaptan). Maybe size, rather than reactivity matters, since inorganic hydrogen sulfide is considerably smaller than organic thiols and may enter proteins and enzymes considerably more easily than, let's say, allyl mercaptan or the established inhibitor D-penicillamine.

Overall, there is therefore still plenty of scope for exciting new studies on hydrogen sulfide in biology. This area of research is particularly interesting since it brings together natural products research, bioorganic and bioinorganic chemistry, complex chemistry, biological sulfur redox chemistry, signal transduction and cellular control, plant and human biology, medicine and drug development. As a highly challenging, emerging multidisciplinary field of research it provides ample opportunities for natural products researchers, chemists, biochemists, biologists, pharmacologists and medical researchers to engage with these topics and each other.

\section{Acknowledgements \\ $\nabla$}

The authors would like to thank David Sadler Bridge and Murree Groom [both ECOspray Ltd. (UK)] and Prof. Eric Block (University of Albany, State University of New York, USA) for many helpful discussions and advice. This work was supported financially by the University of Saarland, the German Academic Exchange Service (DAAD), the Ministry of Economics and Science of Saar- land and the Foundation for Scientific Cooperation between Germany and Luxembourg.

\section{References}

1 Jacob C. A scent of therapy: pharmacological implications of natural products containing redox-active sulfur atoms. Nat Prod Rep 2006; 23: $851-63$

2 Das DK. Hydrogen sulfide preconditioning by garlic when it starts to smell. Am J Physiol Heart Circ Physiol 2007; 293: H2629-H30

3 Block E. The organosulfur chemistry of the genus Allium - implications for the organic chemistry of sulfur. Angew Chem Int Ed Engl 1992; 31: $1135-78$

4 Biteau B, Labarre J, Toledano MB. ATP-dependent reduction of cysteine-sulphinic acid by S-cerevisiae sulphiredoxin. Nature 2003; 425: $980-4$

5 Giles GI, Tasker KM, Jacob C. Hypothesis: The role of reactive sulfur species in oxidative stress. Free Radic Biol Med 2001; 31: 1279-83

6 Munday R, Munday J, Munday CM. Comparative effects of mono-, di-, tri-, and tetrasulfides derived from plants of the allium family: Redox cycling in vitro and hemolytic activity and phase 2 enzyme induction in vivo. Free Radic Biol Med 2003; 34: 1200-11

7 Xiao D, Herman-Antosiewicz A, Antosiewicz J, Xiao H, Brisson M, Lazo JS et al. Diallyl trisulfide-induced G(2)-M phase cell cycle arrest in human prostate cancer cells is caused by reactive oxygen species-dependent destruction and hyperphosphorylation of Cdc25C. Oncogene 2005; 24: 6256-68

8 Hosono T, Fukao T, Ogihara J, Ito Y, Shiba H, Seki T et al. Diallyl trisulfide suppresses the proliferation and induces apoptosis of human colon cancer cells through oxidative modification of beta-tubulin. J Biol Chem 2005; 280: 41487-93

9 Ha MW, Ma R, Shun LP, Gong YH, Yuan Y. Effects of allitridi on cell cycle arrest of human gastric cancer cells. World J Gastroenterol 2005; 11: $5433-7$

10 Jakubíková J, SedlákJ. Garlic-derived organosulfides induce cytotoxicity, apoptosis, cell cycle arrest and oxidative stress in human colon carcinoma cell lines. Neoplasma 2006; 53: 191 -9

11 Anwar A, Burkholz T, Scherer C, Abbas M, Lehr CM, Diederich M et al. Naturally occurring reactive sulfur species, their activity against Caco-2 cells, and possible modes of biochemical action. J Sulfur Chem 2008; 29: $251-68$

12 Jacob C, Anwar A. The chemistry behind redox regulation with a focus on sulphur redox systems. Physiol Plant 2008; 133: 469-80

13 Steudel $R$. The chemistry of organic polysulfanes R-S-n-R $(n>2)$. Chem Rev 2002; 102: 3905-45

14 Muenchberg U, Anwar A, Mecklenburg S, Jacob C. Polysulfides as biologically active ingredients of garlic. Org Biomol Chem 2007; 5: 1505 - 18

15 Benavides GA, Squadrito GL, Mills RW, Patel HD, Isbell TS, Patel RP et al. Hydrogen sulfide mediates the vasoactivity of garlic. Proc Natl Acad Sci USA 2007; 104: $17977-82$

16 Benavides GA, Mills RW, Squadrito GL, Doeller JE, Kraus DW. Effectiveness of garlic-derived sulfur compounds in H2S-Mediated vasoactivity. Free Radic Biol Med 2006; 41: S19-S20

17 Chuah SC, Moore PK, Zhu YZ. S-Allylcysteine mediates cardioprotection in an acute myocardial infarction rat model via a hydrogen sulfidemediated pathway. Am J Physiol Heart Circ Physiol 2007; 293: H2693 - H701

18 Li L, Moore PK. An overview of the biological significance of endogenous gases: new roles for old molecules. Biochem Soc Trans 2007; 35: $1138-41$

19 Fiorucci S, Distrutti E, Cirino G, Wallace JL. The emerging roles of hydrogen sulfide in the gastrointestinal tract and liver. Gastroenterology 2006; 131: $259-71$

20 Durazo-Quiroz F, Pastelâin-Hemâandez G, del Valle-Mondragâon L, Tenorio-Lâopez FA, Torres-NarvâaezJC, Rubio-Donnadieu Fet al. El âoxido nâitrico en medicina. Gac Med Mex 2007; 143: 401 - 14

21 Coburn RF, Blakemore WS, Forster RE. Endogenous carbon monoxide production in man. J Clin Invest 1963; 42: 1172-8

22 Abe K, Kimura $H$. The possible role of hydrogen sulfide as an endogenous neuromodulator. J Neurosci 1996; 16: 1066 - 71

23 Szabo C. Hydrogen sulphide and its therapeutic potential. Nat Rev Drug Discov 2007; 6: 917 - 35

24 Wallace JL. Hydrogen sulfide-releasing anti-inflammatory drugs. Trends Pharmacol Sci 2007; 28: $501-5$ 
25 Lowicka E, Beltowski J. Hydrogen sulfide $\left(\mathrm{H}_{2} \mathrm{~S}\right)$ - the third gas for interest for pharmacologists. Pharmacol Rep 2007; 59: 4-24

26 Chen $C Q$ Xin $H, Z h u Y Z$. Hydrogen sulfide: third gaseous transmitter, but with great pharmacological potential. Acta Pharmacol Sin 2007; 28: $1709-16$

27 Kraus JP, Janosik M, Kozich V, Mandell R, Shih V, Sperandeo MP et al. Cystathionine beta-synthase mutations in homocystinuria. Hum Mutat 1999; 13: $362-75$

28 Zhao WM, Zhang J, Lu YJ, Wang $R$. The vasorelaxant effect of $\mathrm{H}_{2} \mathrm{~S}$ as a novel endogenous gaseous K-ATP channel opener. Embo J 2001; 20 : $6008-16$

29 Li L, Whiteman M, Guan YY, Neo KL, Cheng Y, Lee SW et al. Characterization of a novel, water-soluble hydrogen sulfide-releasing molecule (GYY4137): New insights into the biology of hydrogen sulfide. Circulation 2008; 117: 2351 - 60

30 Coleman JE. Mechanism of action of carbonic anhydrase-substrate sulfonamide and anion binding. J Biol Chem 1967; 242: 5212 -9

31 Leffler C, Parfenova H, Jaggar JH, Wang R. Carbon monoxide and hydrogen sulfide: gaseous messengers in cerebrovascular circulation. J Appl Physiol 2006; 100: 1065-76

32 Wang $R$. Two's company, three's a crowd: can $\mathrm{H}_{2} \mathrm{~S}$ be the third endogenous gaseous transmitter? FASEB J 2002; 16: $1792-8$

33 Papenbrock J, Reimenschneider A, Kamp A, Schulz-Vogt HN, Schmidt A. Characterization of cysteine-degrading and $\mathrm{H}_{2} \mathrm{~S}$-releasing enzymes of higher plants - From the field to the test tube and back. Plant Biol 2007; 9: $582-8$

34 Kopriva S. Regulation of sulfate assimilation in Arabidopsis and beyond. Ann Bot 2006; 97: 479-95

35 Rodrigue R, Jordan JW, Hollis JP. Nematodes - biological control in rice fields - role of hydrogen sulfide. Science 1965; 148: 524-6

36 Miller DL, Roth MB. Hydrogen sulfide increases thermotolerance and lifespan in Caenorhabditis elegans. Proc Natl Acad Sci USA 2007; 104: 20618-22

37 Blachier F, Mariotti F, Huneau JF, Tome D. Effects of amino acid-derived luminal metabolites on the colonic epithelium and physiopathological consequences. Amino Acids 2007; 33: 547-62

38 Levine J, Ellis CJ, Furne JK, Springfield J, Levitt MD. Fecal hydrogen sulfide production in ulcerative colitis. Am J Gastroenterol 1998; 93: $83-7$
39 Suarez F, Furne J, Springfield J, Levitt M. Production and elimination of sulfur-containing gases in the rat colon. Am J Physiol Gastrointest Liver Physiol 1998; 37: G727-G33

40 Washio J, Sato T, Koseki T, Takahashi N. Hydrogen sulfide-producing bacteria in tongue biofilm and their relationship with oral malodour. J Med Microbiol 2005; 54: 889-95

41 Mendes-Ferreira A, Mendes-Faia A, Leao C. Survey of hydrogen sulphide production by wine yeasts. J Food Protect 2002; 65: 1033-7

42 Mahattanatawee K, Perez-Cacho PR, Davenport T, Rouseff R. Comparison of three lychee cultivar odor profiles using gas chromatographyolfactometry and gas chromatography-sulfur detection. J Agric Food Chem 2007; 55: 1939-44

43 Miyazawa M, Osman F. Headspace constituents of Parkia speciosa seeds. Nat Prod Lett 2001; 15: 171-6

44 Chatterji T, Keerthi K, Gates KS. Generation of reactive oxygen species by a persulfide (BnSSH). Bioorg Med Chem Lett 2005; 15: 3921 - 4

45 Jansson EA, Huang L, Malkey R, Govoni M, Nihlén C, Olsson A et al. A mammalian functional nitrate reductase that regulates nitrite and nitric oxide homeostasis. Nat Chem Biol 2008; 4: 411 - 7

46 Kamoun $P$. Endogenous production of hydrogen sulfide in mammals. Amino Acids 2004; 26: 243-54

47 Ashby MT, Aneetha H. Reactive sulfur species: Reactions of hypothiocyanite. J Inorg Biochem 2003; 96: 96-

48 Ashby MT, Aneetha H. Reactive sulfur species: aqueous chemistry of sulfenyl thiocyanates. J Am Chem Soc 2004; 126: 10216-7

49 Nagy P, Ashby MT. Reactive sulfur species: Kinetics and mechanisms of the oxidation of cysteine by hypohalous acid to give cysteine sulfenic acid. J Am Chem Soc 2007; 129: 14082 - 91

50 Whiteman M, Li L, Kostetski I, Chu SH, Siau JL, Bhatia M, Moore PK. Evidence for the formation of a novel nitrosothiol from the gaseous mediators nitric oxide and hydrogen sulphide. Biochem Biophys Res Commun 2006; 343: $303-10$

51 Ali MY, Ping CY, Mok YYP, Ling L, Whiteman M, Bhatia M, Moore PK. Regulation of vascular nitric oxide in vitro and in vivo; a new role for endogenous hydrogen sulphide? Br J Pharmacol 2006; 149: 625 - 34

52 Sun X, Guo T, He J, Zhao MH, Yan M, Cui FD et al. Determination of the concentration of diallyl trisulfide in rat whole blood using gas chromatography with electron-capture detection and identification of its major metabolite with gas chromatography mass spectrometry. Yakugaku Zasshi 2006; 126: 521 - 7 